\title{
Drug Interactions in Parkinson's Disease: Safety of Pharmacotherapy for Arterial Hypertension
}

\author{
Anna Bitner · Paweł Zalewski · Jacek J. Klawe • \\ Julia L. Newton
}

Published online: 27 January 2015

(c) The Author(s) 2015. This article is published with open access at Springerlink.com

\begin{abstract}
Background Parkinson's disease (PD) is a progressive neurodegenerative disorder of the central nervous system, observed in patients aged older than 50 years. In this study, we review interactions between therapies used in PD and selected antihypertensive agents. Moreover, in view of the lack of evidence-based recommendations regarding the pharmacotherapy of arterial hypertension in PD patients, we propose effective and safe therapeutic algorithms for these two coexisting conditions.

Method We used the "Drug interactions" database affiliated with the Ministry of Health, which allows for the identification of interactions between compared active compounds. The database is updated on a monthly basis and all data are consistent with current legislation. For information about interactions, we additionally added data from the British National Formulary, a joint publication of the British Medical Association and the Royal Pharmaceutical Society of Great Britain. In this analysis, we also used data from Micromedex ${ }^{\circledR}$, Cerner Multum ${ }^{\mathrm{TM}}$, Wolters Kluwer $^{\mathrm{TM}}$, Lexicomp ${ }^{\circledR}$ and Stockley's ${ }^{\circledR}$. We analysed the potential interactions between antihypertensive and antiparkinsonian agents included in respective guidelines on the pharmacotherapy of these conditions.
\end{abstract}

\footnotetext{
A. Bitner $(\bowtie) \cdot$ P. Zalewski $\cdot$ J. J. Klawe

Chair and Department of Hygiene and Epidemiology,

The Ludwik Rydygier Collegium Medicum in Bydgoszcz,

The Nicolaus Copernicus University in Torun,

M. Sklodowskiej-Curie 9, 85-094 Bydgoszcz, Poland

e-mail: aniab@doktornat.umk.pl
}

\section{J. L. Newton}

Institute for Ageing and Health, The Medical School, Newcastle University, Framlington Place, Newcastle-upon-Tyne NE2 4HH, Great Britain
Results Our analysis revealed the lack of clinically relevant interactions between preparations of levodopa and benserazide (used for the treatment of PD) and angiotensinconverting enzyme inhibitors, antagonists of $\mathrm{AT}_{1}$ receptor for angiotensin II or antagonists of $\beta$-adrenoreceptors ( $\beta$ adrenolytics).

Conclusion To avoid major drug-to-drug interactions, patients receiving preparations of levodopa and benserazide should be prescribed angiotensin-converting enzyme inhibitors, antagonists of $\mathrm{AT}_{1}$ receptor for angiotensin II, or antagonists of $\beta$-adrenoreceptors ( $\beta$-adrenolytics) as the first-line agents of antihypertensive treatment.

\section{Key Points}

We lack detailed guidelines on the pharmacotherapy of arterial hypertension in patients with Parkinson's disease.

Pharmacotherapy of arterial hypertension in this group should be individualised.

Angiotensin-converting enzyme inhibitors, antagonists of $\mathrm{AT}_{1}$ receptor for angiotensin II or antagonists of $\beta$-adrenoreceptors seem to be the safest option of hypotensive treatment for patients with Parkinson's disease.

\section{Introduction}

Parkinson's disease (PD) is a progressive neurodegenerative disorder of the central nervous system, most frequently observed in patients aged older than 50 years. The 
pathomechanism of PD is associated with the death of dopamine-generating cells in the midbrain's substantia nigra. The concomitant degeneration of other neurons is reflected by disorders in the cholinergic, noradrenergic and serotoninergic systems. The death of approximately $80 \%$ of the dopamine-generating cells is reflected by an evident loss of muscular control, which manifests as a slowness of movement, balancing disorders, rigidity and spasticity of muscles, and shaking of the limbs and head. Furthermore, many patients experience orthostatic impairment of circulatory regulation at advanced stages of PD. Orthostatic hypotension is the most frequent cardiovascular condition associated with PD. It is usually defined as a drop in systolic blood pressure by at least $20 \mathrm{~mm} \mathrm{Hg}$ during the initial 3 min of verticalisation [1-4].

Epidemiological data suggest that about $50 \%$ of patients with PD experience concomitant orthostatic hypotension and arterial hypertension (especially in the supine position). The signs of arterial hypertension and orthostatic hypotension reduce the quality of life of patients and represent an important therapeutic problem [5-9].

Antihypertensive agents can exacerbate the signs of orthostatic hypotension or interact with drugs used in PD, thus aggravating the symptoms of this condition. However, untreated PD-related arterial hypertension can result in left ventricular hypertrophy. Still, there is a lack of evidencebased recommendations regarding the pharmacotherapy of arterial hypertension in PD patients. Therefore, the choice of antihypertensive agents in patients with co-existing PD should be based on a 24 -h profile of blood pressure, taking into account the interactions between antihypertensive and anti-parkinsonian agents. Often, improper pharmacotherapy of arterial hypertension can enhance the signs of PD and as a consequence decreasing the quality of a patient's life [10-15].

Because of their clinical importance, drug-to-drug interactions can be classified as major/significant (life threatening), moderate (requiring additional interventions) and minor/insignificant (without clinical consequences). The knowledge of drug-to-drug interactions by clinicians is vitally important as it enables them to predict potential risks associated with prescription of a given agent. However, the effect of a given interaction and its severity may differ significantly from patient to patient. Older individuals constitute a particular risk group for drug-to-drug interactions; this results mostly from the presence of numerous comorbidities and age-related changes in pharmacokinetics [16].

\section{Aim of the Study}

The aim of this study was to analyse the interactions between selected anti-parkinsonian and antihypertensive agents in view of international guidelines on the pharmacotherapy of these conditions [17-19]. Moreover, based on this analysis, we aimed to develop recommendations regarding effective and safe therapy of arterial hypertension coexisting with PD. We summarise the risks and benefits of current treatments.

\section{Method}

We used the "Drug interactions" database affiliated with the Ministry of Health, Poland, which allows for the identification of interactions between compared active compounds. The database was developed in cooperation with researchers from the Faculty of Pharmacology, Collegium Medicum at Jagiellonian University in Cracow, Poland. The database is updated on a monthly basis and all data are consistent with current legislation. The programme "Drug interactions" allows the analysis of the potential interactions between antihypertensive and anti-parkinsonian agents and the determination of the degree of the clinical gravity of the drug-drug interactions (no interactions, non-significant interactions, significant interactions, very significant interactions).

For information about interactions, we added data from the British National Formulary, a joint publication of the British Medical Association and the Royal Pharmaceutical Society of Great Britain. In this analysis, we also used data from Micromedex ${ }^{\circledR}$, Cerner Multum ${ }^{\mathrm{TM}}$, Wolters Kluwer $^{\mathrm{TM}}$, Lexicomp ${ }^{\circledR}$ and Stockley's ${ }^{\circledR}$.

We analysed the potential interactions between antihypertensive and anti-parkinsonian agents included in respective guidelines on the pharmacotherapy of these conditions.

\section{Results}

\section{Diuretics}

Diuretics constitute a group of drugs that are inhomogeneous in terms of structure and target site within the nephron. According to the American guidelines (JNC-7 2003), diuretics are recommended as the first-line group of agents in the therapy of arterial hypertension. Diuretics can be classified as thiazides and thiazide-like agents (chlorothiazide, hydrochlorothiazide, trichloromethiazide, bendroflumethiazide, chlorthalidone, indapamide), loop diuretics (furosemide, etacrine acid, piretanide, torasemide) and potassium-sparing diuretics (amiloride, spironolactone, triamterene).

Owing to their mechanism of action, diuretics can be divided into those acting in the proximal tubules 
(sulphonamide-acetazolamide), loop diuretics (chlorobenzenesulfonamide and dichlorophenoxyacetic acid derivatives), agents acting in the cortical part of the distal convoluted tubules (thiazides and heterocyclic thiazides), agents acting in the collecting ducts (aldosterone antagonists and agents acting independently of aldosterone), xanthine diuretics and osmotic diuretics [20, 21].

\section{Thiazides and Thiazide-like Agents}

Diuretics, especially thiazide (hydrochlorothiazide) and thiazide-like agents (chlorthalidone, indapamide), are the most frequently used antihypertensive drugs. The mechanism of their action is associated with blocking the resorption of sodium ions $\left(\mathrm{Na}^{+}\right)$in the cortical part of the ascending arm of the nephron loop and in the proximal part of the distal tubule. Because they decrease urinary elimination of calcium, thiazides and thiazide-like diuretics can contribute to hypercalcemia. Additionally, similarly to loop diuretics, they increase urinary elimination of potassium and increase blood concentration of uric acid (hyperuricemia) [22-24].

The effects of agents used in PD can be modified as a result of both pharmacokinetic and pharmacodynamic interactions. The interaction between hydrochlorothiazide and anti-parkinsonian agents, such as amantadine and combination of levodopa with benserazide, is significant. Concurrent administration of hydrochlorothiazide and amantadine can cause very significant drugdrug pharmacokinetic interactions. This is reflected by a marked increase in amantadine concentration, resulting from the inhibition of the tubular secretion of this agent by hydrochlorothiazide, and aggravation of its side effects, such as nausea, sleeplessness, vertigo, problems with concentration, orthostatic drop in blood pressure, peripheral edema, memory loss, depression, seizure, heart failure, ocular irritation, hypertension, changes in blood morphology, psychoses, speech disorders, skin hypersensitivity and photophobia. In such cases, a thiazide diuretic should be discontinued and the dose of amantadine should be reduced or replaced with another agent.

Concurrent administration of hydrochlorothiazide and levodopa in combination with benserazide or hydrochlorothiazide, chlorthalidone, indapamide and levodopa in combination with benserazide and entacapone leads to significant drug-drug pharmacokinetic interactions, resulting in an enhanced hypotensive effect. This can be associated with orthostatic hypotension.

Combination of bromocriptine or cabergoline with hydrochlorothiazide leads to a non-significant interaction associated with possible aggravation of the hypotensive effect of the diuretic.
Concurrent use of indapamide and amantadine can be reflected by significant interaction characterised by the aggravation of the side effects of the anti-parkinsonian agent. In such cases, the thiazide diuretic should be withdrawn and the dose of amantadine should be reduced or replaced with another agent.

Administration of indapamide along with levodopa in combination with benserazide can significantly enhance the hypotensive effect, which, similarly to interaction with hydrochlorothiazide, leads to orthostatic hypotension.

Indapamide in combination with biperiden leads to insignificant interaction associated with the stimulation of the diuretic effect, resulting from its faster absorption from the alimentary tract.

Data sources include Micromedex ${ }^{\circledR}$, updated May 6th, 2014, Cerner Multum ${ }^{\text {TM }}$, updated June 16th, 2014 and Wolters Kluwer $^{\mathrm{TM}}$, updated June 12th, 2014.

Table 1 presents the interactions between thiazide and thiazide-like agents most frequently used in the treatment of arterial hypertension and anti-parkinsonian agents, stratified according to their significance.

\section{Loop Diuretics}

Loop diuretics (furosemide, etacrine acid, piretanide, torasemide) exert stronger hypotensive effect than thiazide diuretics. They act in the ascending part of the loop of Henle. About $30 \%$ of the glomerular load of $\mathrm{Na}^{+}$and $\mathrm{Cl}^{-}$ is absorbed in this part of the nephron, along with $\mathrm{K}^{+}$, and large amounts of $\mathrm{Ca}^{2+}$ and $\mathrm{Mg}^{2+}$. Loop diuretics inhibit the $\mathrm{Na}^{+2}-\mathrm{Cl}-\mathrm{K}^{+}$co-transporter, enabling the inflow of $\mathrm{Na}^{+}$into the tubular cells. These agents show maximal efficacy because up to $30 \%$ of the glomerular load of $\mathrm{Na}^{+}$ is eliminated with urine as a result of their action. Translocation of large amounts of $\mathrm{Na}^{+}$and $\mathrm{K}^{+}$ions into the distal parts of the nephron stimulates exchange of $\mathrm{Na}^{+}$to $\mathrm{H}^{+}$or $\mathrm{K}^{+}$, potentially contributing to kaliuresis and hypokalemia. Moreover, loop diuretics block resorption of $\mathrm{Ca}^{2+}$ and $\mathrm{Mg}^{2+}$, leading to enhanced urinary elimination of these elements, and contribute to hyperuricemia owing to enhanced renal resorption of uric acid [25, 26].

Significant interaction between furosemide and amantadine, increasing the risk of QT segment prolongation and a torsade de pointes (TdP) type of arrhythmia, should be considered when choosing loop diuretics as antihypertensive agents in individuals with PD. Amantadine and furosemide are both drugs with a conditional risk for TdP. This means that the risk of developing TdP highly depends on other risk factors for this condition (e.g. age, presence of concomitant cardiovascular pathologies, potassium level and renal function). Potassium supplementation can be advised in the case of hypokalemia, but should be accompanied by appropriate monitoring of the potassium 
Table 1 The interactions between thiazide and thiazidelike agents most frequently used in the treatment of arterial hypertension and antiparkinsonian agents, stratified according to their significance
COMT catechol- $O$-methyl transferase, $M A O-B$ monoamine oxidase $\mathrm{B}, 1$ No interactions, 2 non-significant interactions, 3 significant interactions, 4 very significant interactions

\begin{tabular}{|c|c|c|c|}
\hline Drugs & Hydrochlorothiazide & Chlorthalidone & Indapamide \\
\hline \multicolumn{4}{|l|}{ Levodopa preparations } \\
\hline Levodopa + benserazide & 3 & 1 & 3 \\
\hline Levodopa + carbidopa & 1 & 1 & 1 \\
\hline Levodopa + carbidopa + entacapone & 3 & 3 & 3 \\
\hline \multicolumn{4}{|l|}{ Dopamine receptor agonists } \\
\hline Cabergoline & 1 & 1 & 2 \\
\hline Pramipexole & 1 & 1 & 1 \\
\hline Bromocriptine & 1 & 1 & 1 \\
\hline Rotigotine & 1 & 1 & 1 \\
\hline Ropinirole & 1 & 1 & 1 \\
\hline Piribedil & 1 & 1 & 1 \\
\hline \multicolumn{4}{|l|}{ MAO-B inhibitors } \\
\hline Selegiline & 1 & 1 & 1 \\
\hline Rasagiline & 1 & 1 & 1 \\
\hline Amantadine & 4 & 1 & 3 \\
\hline \multicolumn{4}{|l|}{ Cholinolytic agents } \\
\hline Pridinol & 1 & 1 & 1 \\
\hline Biperidene & 1 & 1 & 2 \\
\hline \multicolumn{4}{|l|}{ COMT inhibitors } \\
\hline Tolcapon & 1 & 1 & 1 \\
\hline Entacapone & 1 & 1 & 1 \\
\hline
\end{tabular}

level. Furthermore, amantadine should not be prescribed concomitantly to drugs that prolong the QT interval. Furthermore, this agent is known to escalate the effect of neurostimulatory drugs, thus increasing the risk of neurological side effects (e.g. restlessness, nervousness and sleeplessness) and arrhythmia. We used the "Drug interactions" database affiliated with the Ministry of Health, Poland. Such information was not given in Micromedex ${ }^{\circledR}$, Cerner Multum ${ }^{\mathrm{TM}}$ and Wolters Kluwer ${ }^{\mathrm{TM}}$.

Administration of furosemide or torasemide along with levodopa combined with benserazide or entacapone can significantly enhance the hypotensive effect, which, similarly to the interaction between hydrochlorothiazide and indapamide, aggravates the orthostatic hypotension.

Table 2 presents the interactions between loop diuretics most frequently used in the treatment of arterial hypertension and anti-parkinsonian agents, stratified according to their significance.

\section{Potassium-Sparing Diuretics}

Antikaliuretic diuretics act in the distal part of the nephron (aldosterone antagonists and agents acting independently from aldosterone). They block the sodium channels of collecting tubules involved in the exchange of sodium ions $\mathrm{Na}^{+}$and potassium ions $\mathrm{K}^{+}$, which are further eliminated with urine. Spironolactone is a representative of this group [27].
Significant interaction between spironolactone and levodopa combined with benserazide or entacapone should be considered before the administration of potassiumsparing diuretics as antihypertensive agents in individuals with co-existing PD. Such interaction can enhance hypotensive effect, thus aggravating the orthostatic hypotension. Data sources include Micromedex ${ }^{\circledR}$, updated May 6th, 2014, Cerner Multum ${ }^{\mathrm{TM}}$, updated June 16th, 2014 and Wolters Kluwer $^{\mathrm{TM}}$, updated June 12th, 2014. It is noteworthy that this interaction is not included in Lexicomp ${ }^{\circledR}$ and Stockley's ${ }^{\circledR}$ databases.

Table 3 presents the interactions between potassiumsparing diuretics most frequently used in the treatment of arterial hypertension and anti-parkinsonian agents, stratified according to their significance.

\section{Angiotensin-Converting Enzyme Inhibitors}

According to the 2011 recommendations of the Polish Society for Arterial Hypertension, angiotensin-converting enzyme (ACE) inhibitors can be used in non-complicated arterial hypertension. ACE inhibitors are competitive inhibitors of ACE, which is involved in the transformation of angiotensin I (inactive decapeptide) into angiotensin II. Angiotensin II is one of the strongest endogenous vasoconstrictive factors. Moreover, ACE inhibitors also inhibit kininase II, an enzyme catalyzing degradation of bradykinin and other strong vasodilating peptides. This is reflected 
Table 2 The interactions between loop diuretics most frequently used in the treatment of arterial hypertension and anti-parkinsonian agents, stratified according to their significance

\begin{tabular}{lll}
\hline Drugs & Furosemide & Torasemide \\
\hline Levodopa preparations & & \\
Levodopa + benserazide & 3 & 3 \\
Levodopa + carbidopa & 1 & 1 \\
Levodopa + carbidopa + entacapone & 3 & 3 \\
Dopamine receptor agonists & & \\
Cabergoline & 1 & 1 \\
Pramipexole & 1 & 1 \\
Bromocriptine & 1 & 1 \\
Rotigotine & 1 & 1 \\
Ropinirole & 1 & 1 \\
Piribedil & 1 & 1 \\
MAO-B inhibitors & & \\
Selegiline & 1 & 1 \\
Rasagiline & 1 & 1 \\
Amantadine & $3 *$ & 1 \\
Cholinolytic agents & & 1 \\
Pridinol & 1 & 1 \\
Biperidene & 1 & \\
COMT inhibitors & & 1 \\
Tolcapon & & \\
Entacapone & & 1 \\
\hline COMTC & & 1
\end{tabular}

COMT catechol- $O$-methyl transferase, $M A O-B$ monoamine oxidase B, 1 No interactions, 2 non-significant interactions, 3 significant interactions, 4 very significant interactions

* No information in Micromedex ${ }^{\circledR}$, Cerner Multum ${ }^{\mathrm{TM}}$ and Wolters Kluwer $^{\mathrm{TM}}$

by increased concentration of bradykinin, which stimulates $\beta_{2}$ receptors, as a result increasing the release of nitrogen oxide (NO) and vasoactive prostaglandins, such as prostaglandin E2 or prostacyclins [28-30].

Although ACE inhibitors are not involved in significant interactions with anti-parkinsonian agents according to the Polish ministerial database, Lexicomp ${ }^{\circledR}$ and Stockley's ${ }^{\circledR}$ databases include significant interactions between monoamine oxidase B (MAO-B) inhibitors and ACE inhibitors (level $\mathrm{C}$ in Lexicomp ${ }^{\circledR}$ and monitor level in Stockley's ${ }^{\circledR}$ ). Some drugs (captopril, enalapril, benazepril) cause insignificant drug-drug pharmacokinetic interactions manifested by enhanced hypotensive effect of ACE inhibitors, when combined with bromocriptine and cabergoline. This can be associated with orthostatic hypotension. Although most patients tolerate therapy with ACE inhibitors well, the administration of these agents can be associated with adverse effects, such as orthostatic hypotension, dry cough, hyperkalemia, acute renal failure, proteinuria and vasoactive oedema [28-30].
Table 3 The interactions between potassium-sparing diuretics most frequently used in the treatment of arterial hypertension and antiparkinsonian agents, stratified according to their significance

\begin{tabular}{ll}
\hline Drugs & Spironolactone \\
\hline Levodopa preparations & \\
Levodopa + benserazide & $3^{*}$ \\
Levodopa + carbidopa & 1 \\
Levodopa + carbidopa + entacapone & $3^{*}$ \\
Dopamine receptor agonists & \\
Cabergoline & 1 \\
Pramipexole & 1 \\
Bromocriptine & 1 \\
Rotigotine & 1 \\
Ropinirole & 1 \\
Piribedil & 1 \\
MAO-B inhibitors & \\
Selegiline & 1 \\
Rasagiline & 1 \\
Amantadine & 1 \\
Cholinolytic agents & \\
Pridinol & 1 \\
Biperidene & \\
COMT inhibitors & 1 \\
Tolcapon & \\
Entacapone & 1 \\
\hline
\end{tabular}

COMT catechol- $O$-methyl transferase, $M A O-B$ monoamine oxidase $\mathrm{B}, 1$ No interactions, 2 non-significant interactions, 3 significant interactions, 4 very significant interactions

* No information in Lexicomp ${ }^{\circledR}$ and Stockley's ${ }^{\circledR}$ databases

Considering the fact that orthostatic hypotension is the most frequent cardiovascular disorder associated with PD, its occurrence as an adverse effect of ACE inhibitors is undesirable. The signs of hypotonia associated with the use of ACE inhibitors can result from the lack of vascular tone, normally induced by angiotensin II. This is particularly evident in individuals with high plasma activity of renin, in particular following the administration of the initial dose [28-30].

Table 4 presents the interactions between ACE inhibitors most frequently used in the treatment of arterial hypertension and anti-parkinsonian agents, stratified according to their significance.

\section{Antagonists of $\mathrm{AT}_{1}$ Receptor for Angiotensin II}

The mechanism behind the hypotensive effect of antagonists of $\mathrm{AT}_{1}$ receptor for angiotensin $\mathrm{II}$ is associated with the binding of the drug to $\mathrm{AT}_{1}$ receptor for angiotensin II (AT II) in adrenal glands and smooth muscles of the blood vessels. This prevents the vasoconstrictive effect of angiotensin II and aldosterone release. Of note, the 
antagonists of $\mathrm{AT}_{1}$ receptor for angiotensin II do not modulate the metabolism of bradykinin, noradrenalin and substance P [31-34].

Data from the Polish ministerial database suggest that the antagonists of $\mathrm{AT}_{1}$ receptor for angiotensin II do not interact with anti-parkinsonian agents, apart from an insignificant interaction between sartans and bromocriptine or cabergoline, which is associated with the enhancement of their hypotensive effect [31-34]. In contrast, Lexicomp ${ }^{\circledR}$ and Stockley's ${ }^{\circledR}$ include significant interactions between MAO-B inhibitors and antagonists of AT1 receptor.

Table 5 presents the interactions between the antagonists of $\mathrm{AT}_{1}$ receptor for angiotensin II most frequently used in the treatment of arterial hypertension and antiparkinsonian agents, stratified according to their significance.

\section{Calcium Channel Antagonists}

Calcium channel antagonists constitute the most popular group of antihypertensive agents. Three groups of drugs are used most often: dihydropyridine derivatives (nifedipine, amlodipine), phenylalkylamines (verapamil) and benzothiazepines (diltiazem). These groups differ in terms of their pharmacological properties and chemical structure. The mechanism underlying the effects of calcium channel antagonists pertains to blocking calcium channels, which results in the inhibition of the intracellular inflow of $\mathrm{Ca}^{2+}$ ions. Free intracellular $\mathrm{Ca}^{2+}$ ions regulate the tonus of vascular smooth muscles. Therefore, the blockade of the intracellular inflow of $\mathrm{Ca}^{2+}$ is reflected by decreased vascular tone, reduced peripheral resistance and subsequent drop in blood pressure [35-38].

There are noteworthy interactions between nifedipine, amlodipine, felodipine, isradipine, nitrendipine, verapamil or diltiazem and anti-parkinsonian agents, such as bromocriptine, ropinirole or levodopa combined with benserazide. Concurrent administration of the abovementioned agents and levodopa combined with benserazide or entacapone can lead to insignificant drug-drug interaction at the pharmacokinetic phase. This can be reflected by the impairment of synaptic transmission by calcium channel antagonists and the weaker effect of levodopa and benserazide. Moreover, the previously mentioned antihypertensive agents can be involved in insignificant interactions with bromocriptine, resulting in the enhanced hypotensive effect. Combining nifedipine, nitrendipine, verapamil or diltiazem with ropinirole is associated with the risk of bradycardia, arrhythmia and excessive decrease in blood pressure; this latter can be also a consequence of the interaction between amlodipine or isradipine and ropinirole. Nifedipine, amlodipine, felodipine, isradipine, nitrendipine, verapamil and diltiazem can also insignificantly interact with cabergoline (with the exception of
Table 4 The interactions between angiotensin-converting enzyme inhibitors most frequently used in the treatment of arterial hypertension and anti-parkinsonian agents, stratified according to their significance
COMT catechol- $O$-methyl transferase, $M A O-B$ monoamine oxidase B, 1 No interactions, 2 non-significant interactions, 3 significant interactions, 4 very significant interactions

\begin{tabular}{|c|c|c|c|c|c|c|}
\hline Drugs & Captopril & Enalapril & Benazepril & Lisinopril & Ramipril & Imidapril \\
\hline \multicolumn{7}{|l|}{ Levodopa preparations } \\
\hline Levodopa + benserazide & 1 & 1 & 1 & 1 & 1 & 1 \\
\hline Levodopa + carbidopa & 1 & 1 & 1 & 1 & 1 & 1 \\
\hline $\begin{array}{l}\text { Levodopa + carbidopa } \\
+ \text { entacapone }\end{array}$ & 1 & 1 & 1 & 1 & 1 & 1 \\
\hline \multicolumn{7}{|l|}{ Dopamine receptor agonists } \\
\hline Cabergoline & 2 & 2 & 2 & 2 & 1 & 1 \\
\hline Pramipexole & 1 & 1 & 1 & 1 & 1 & 1 \\
\hline Bromocriptine & 2 & 2 & 2 & 1 & 1 & 1 \\
\hline Rotigotine & 1 & 1 & 1 & 1 & 1 & 1 \\
\hline Ropinirole & 1 & 1 & 1 & 1 & 1 & 1 \\
\hline Piribedil & 1 & 1 & 1 & 1 & 1 & 1 \\
\hline \multicolumn{7}{|l|}{ MAO-B inhibitors } \\
\hline Selegiline & 1 & 1 & 1 & 1 & 1 & 1 \\
\hline Rasagiline & 1 & 1 & 1 & 1 & 1 & 1 \\
\hline Amantadine & 1 & 1 & 1 & 1 & 1 & 1 \\
\hline \multicolumn{7}{|l|}{ Cholinolytic agents } \\
\hline Pridinol & 1 & 1 & 1 & 1 & 1 & 1 \\
\hline Biperidene & 1 & 1 & 1 & 1 & 1 & 1 \\
\hline \multicolumn{7}{|l|}{ COMT inhibitors } \\
\hline Tolcapon & 1 & 1 & 1 & 1 & 1 & 1 \\
\hline Entacapone & 1 & 1 & 1 & 1 & 1 & 1 \\
\hline
\end{tabular}


Table 5 The interactions between the antagonists of $\mathrm{AT}_{1}$ receptor for angiotensin II most frequently used in the treatment of arterial hypertension and anti-parkinsonian agents, stratified according to their significance
$C O M T$ catechol- $O$-methyl transferase, $M A O-B$ monoamine oxidase $\mathrm{B}, 1$ No interactions, 2 non-significant interactions, 3 significant interactions, 4 very significant interactions

* Lexicomp ${ }^{\circledR}$ and Stockley's ${ }^{\circledR}$ include significant interactions between MAO-B inhibitors and $\mathrm{AT}_{1}$ receptor

\begin{tabular}{|c|c|c|c|c|c|}
\hline Drugs & Eprosartan & Irbesartan & Losartan & Telmisartan & Valsartan \\
\hline \multicolumn{6}{|l|}{ Levodopa preparations } \\
\hline Levodopa + benserazide & 1 & 1 & 1 & 1 & 1 \\
\hline Levodopa + carbidopa & 1 & 1 & 1 & 1 & 1 \\
\hline Levodopa + carbidopa + entacapone & 1 & 1 & 1 & 1 & 1 \\
\hline \multicolumn{6}{|l|}{ Dopamine receptor agonists } \\
\hline Cabergoline & 2 & 2 & 2 & 2 & 2 \\
\hline Pramipexole & 1 & 1 & 1 & 1 & 1 \\
\hline Bromocriptine & 2 & 2 & 2 & 2 & 2 \\
\hline Rotigotine & 1 & 1 & 1 & 1 & 1 \\
\hline Ropinirole & 1 & 1 & 1 & 1 & 1 \\
\hline Piribedil & 1 & 1 & 1 & 1 & 1 \\
\hline \multicolumn{6}{|l|}{ MAO-B inhibitors } \\
\hline Selegiline & $1^{*}$ & $1^{*}$ & $1^{*}$ & $1^{*}$ & $1^{*}$ \\
\hline Rasagiline & $1^{*}$ & $1 *$ & $1 *$ & $1^{*}$ & $1^{*}$ \\
\hline Amantadine & 1 & 1 & 1 & 1 & 1 \\
\hline \multicolumn{6}{|l|}{ Cholinolytic agents } \\
\hline Pridinol & 1 & 1 & 1 & 1 & 1 \\
\hline Biperidene & 1 & 1 & 1 & 1 & 1 \\
\hline \multicolumn{6}{|l|}{ COMT inhibitors } \\
\hline Tolcapon & 1 & 1 & 1 & 1 & 1 \\
\hline Entacapone & 1 & 1 & 1 & 1 & 1 \\
\hline
\end{tabular}

verapamil, which shows a significant interaction), leading to the enhancement of the hypotensive effect of these agents. It should be noted that, contrary to the Polish database, Lexicomp ${ }^{\circledR}$ and Stockley's ${ }^{\circledR}$ databases include significant interactions between MAO-B inhibitors and calcium channel antagonists. Data from: Micromedex ${ }^{\circledR}$, Cerner Multum ${ }^{\mathrm{TM}}$ and Wolters Kluwer $^{\mathrm{TM}}$ also include significant interactions between MAO-B inhibitors and calcium channel antagonists. For example, selegiline and amlodipineine may have additive effects in lowering a patient's blood pressure.

Table 6 presents the interactions between calcium channel antagonists most frequently used in the treatment of arterial hypertension and anti-parkinsonian agents, stratified according to their significance.

\section{Antagonists of $\beta$-Adrenoreceptors ( $\beta$-Adrenolytics)}

Antagonists of $\beta$-adrenoreceptors bind selectively to $\beta$ adrenergic receptors and cause competitive reversible antagonism of $\beta$-adrenergic stimulation of various organs. The mechanism of their action is variable and not completely understood as suggested by differences in the effects of various drugs from this group.

$\beta$-Adrenolytic agents are classified into several categories; namely, non-selective and selective antagonists of $\beta$-adrenoreceptors. Non-selective $\beta$-adrenolytics causing competitive blockade of $\beta_{1}$ and $\beta_{2}$ receptors with intrinsic sympathomimetic activity include nadolol, propranolol, tymolol and sotalol, while the group of agents without such activity encompasses pindolol, carteolol, penbutolol, oxprenolol and alprenolol. Similarly, there are selective $\beta$-adrenolytics with intrinsic sympathomimetic activity, such as atenolol, bisoprolol, metoprolol and betaxolol, or without such activity, e.g. acebutolol. Moreover, there is a group of $\alpha$ - and $\beta$ adrenolytics that act as peripheral vasodilators by blocking $\alpha_{1}$-adrenergic receptor (labetalol, carvedilol, bucindolol) [39-42].

Interactions between agents such as acebutolol, bisoprolol, propranolol and metoprolol and such anti-parkinsonian agents as bromocriptine, selegiline or ropinirole should be considered. Concurrent administration of the abovementioned $\beta$-adrenolytics and selegiline is reflected by very significant interaction associated with the risk of bradycardia and potentially dangerous reversal of $\beta$ receptor blockade.

Moreover, a significant interaction between such active compounds as acebutolol, atenolol, bisoprolol, carvedilol, metoprolol, nebivolol or pindolol and ropinirole can occur, with subsequent risk of bradycardia, arrhythmia and excessive drop in blood pressure. The abovementioned $\beta$ adrenolytics also insignificantly interact with bromocriptine and cabergoline (and also, in the case of carvedilol, 
Table 6 The interactions between calcium channel antagonists most frequently used in the treatment of arterial hypertension and antiparkinsonian agents, stratified according to their significance

\begin{tabular}{|c|c|c|c|c|c|c|c|c|}
\hline Drugs & Nifedipine & Amlodipine & Felodipine & Isradipine & Lacidipine & Nitrendipina & Verapamil & Diltiazem \\
\hline \multicolumn{9}{|l|}{ Levodopa preparations } \\
\hline Levodopa + benserazide & 2 & 2 & 2 & 2 & 1 & 2 & 2 & 2 \\
\hline Levodopa + carbidopa & 1 & 1 & 1 & 1 & 1 & 1 & 1 & 1 \\
\hline $\begin{array}{l}\text { Levodopa }+ \text { carbidopa } \\
+ \text { entacapone }\end{array}$ & 2 & 2 & 2 & 2 & 1 & 2 & 2 & 2 \\
\hline \multicolumn{9}{|l|}{ Dopamine receptor agonists } \\
\hline Cabergoline & 2 & 2 & 2 & 2 & 1 & 2 & 3 & 2 \\
\hline Pramipexole & 1 & 1 & 1 & 1 & 1 & 1 & 1 & 1 \\
\hline Bromocriptine & 2 & 2 & 2 & 2 & 1 & 2 & 2 & 2 \\
\hline Rotigotine & 1 & 1 & 1 & 1 & 1 & 1 & 1 & 1 \\
\hline Ropinirole & 3 & 3 & 1 & 3 & 1 & 3 & 3 & 3 \\
\hline Piribedil & 1 & 1 & 1 & 1 & 1 & 1 & 1 & 1 \\
\hline \multicolumn{9}{|l|}{ MAO-B inhibitors } \\
\hline Selegiline & $1^{*}$ & $1 *$ & $1^{*}$ & $1 *$ & $1 *$ & $1 *$ & $1^{*}$ & $1 *$ \\
\hline Rasagiline & $1 *$ & $1^{*}$ & $1 *$ & $1 *$ & $1 *$ & $1 *$ & $1 *$ & $1 *$ \\
\hline Amantadine & 1 & 1 & 1 & 1 & 1 & 1 & 1 & 1 \\
\hline \multicolumn{9}{|l|}{ Cholinolytic agents } \\
\hline Pridinol & 1 & 1 & 1 & 1 & 1 & 1 & 1 & 1 \\
\hline Biperidene & 1 & 1 & 1 & 1 & 1 & 1 & 1 & 1 \\
\hline \multicolumn{9}{|l|}{ COMT inhibitors } \\
\hline Tolcapon & 1 & 1 & 1 & 1 & 1 & 1 & 1 & 1 \\
\hline Entacapone & 1 & 1 & 1 & 1 & 1 & 1 & 1 & 1 \\
\hline
\end{tabular}

$C O M T$ catechol- $O$-methyl transferase, $M A O-B$ monoamine oxidase B, 1 No interaction, 2 non-significant interactions, 3 significant interactions, 4 very significant interactions

$*^{*}$ Lexicomp $^{\circledR}$, Stockley's $^{\circledR}$, Micromedex ${ }^{\circledR}$, Cerner Multum ${ }^{\mathrm{TM}}$, Wolters Kluwer ${ }^{\mathrm{TM}}$ include significant interactions between MAO-B inhibitors and calcium channel antagonists

with biperiden), which can be reflected by the enhancement of their hypotensive effect.

Data sources include Micromedex ${ }^{\circledR}$, updated May 6th, 2014, Cerner Multum ${ }^{\mathrm{TM}}$, updated June 16th, 2014 and Wolters Kluwer ${ }^{\mathrm{TM}}$, updated June 12th, 2014.

Table 7 presents the interactions between antagonists of $\beta$-adrenoreceptors most frequently used in the treatment of arterial hypertension and anti-parkinsonian agents, stratified according to their significance.

\section{Discussion}

At present, we lack detailed guidelines regarding the pharmacotherapy of arterial hypertension and the choice of hypotensive agents for patients with PD. Pharmacotherapy of arterial hypertension in individuals with PD has to be individualised. Achieving the desired effect of hypotensive agents and avoiding adverse effects associated with their interaction with anti-parkinsonian agents constitute prerequisites of efficacious antihypertensive therapy [43-45].
To avoid potential adverse effects, pharmacotherapy of arterial hypertension should begin with the lowest possible dose of the antihypertensive agent. If the results are unsatisfactory, the dose of the single agent should be increased. If monotherapy is unsuccessful, a combination of drugs, preferably originating from various classes and characterised by different modes of action, is recommended. Blood pressure in older patients should be decreased gradually to reduce the incidence of adverse events [46-48].

According to the international guidelines, in the cases where monotherapy with a small dose of antihypertensive agent is insufficient to reduce blood pressure, it should be replaced with another agent at a low dose, its initial dose should be increased or combined therapy should be implemented.

Consideration of a patient's preferences and potential interactions with agents used in the treatment of comorbidities constitutes a prerequisite of successful therapy [46-48].

In view of existing guidelines and evidence of potential interactions between antihypertensive and anti- 
Table 7 The interactions between antagonists of $\beta$-adrenoreceptors most frequently used in the treatment of arterial hypertension and antiparkinsonian agents, stratified according to their significance

\begin{tabular}{|c|c|c|c|c|c|c|c|c|}
\hline Drugs & Acebutolol & Atenolol & Bisoprolol & Carvedilol & Metoprolol & Nebiwolol & Pindolol & Propranolo \\
\hline \multicolumn{9}{|l|}{ Levodopa preparations } \\
\hline Levodopa + benserazide & 1 & 1 & 1 & 1 & 1 & 1 & 1 & 1 \\
\hline Levodopa + carbidopa & 1 & 1 & 1 & 1 & 1 & 1 & 1 & 1 \\
\hline Levodopa + carbidopa + entacapone & 1 & 1 & 1 & 1 & 1 & 1 & 1 & 1 \\
\hline \multicolumn{9}{|l|}{ Dopamine receptor agonists } \\
\hline Cabergoline & 2 & 2 & 2 & 2 & 2 & 2 & 2 & 2 \\
\hline Pramipexole & 1 & 1 & 1 & 1 & 1 & 1 & 1 & 1 \\
\hline Bromocriptine & 2 & 2 & 2 & 2 & 2 & 2 & 2 & 1 \\
\hline Rotigotine & 1 & 1 & 1 & 1 & 1 & 1 & 1 & 1 \\
\hline Ropinirole & 3 & 3 & 3 & 3 & 3 & 3 & 3 & 1 \\
\hline Piribedil & 1 & 1 & 1 & 1 & 1 & 1 & 1 & 1 \\
\hline \multicolumn{9}{|l|}{ MAO-B inhibitors } \\
\hline Selegiline & 4 & 1 & 4 & 1 & 4 & 1 & 1 & 4 \\
\hline Rasagiline & 1 & 1 & 1 & 1 & 1 & 1 & 1 & 1 \\
\hline Amantadine & 1 & 1 & 1 & 1 & 1 & 1 & 1 & 1 \\
\hline \multicolumn{9}{|l|}{ Cholinolytic agents } \\
\hline Pridinol & 1 & 1 & 1 & 1 & 1 & 1 & 1 & 1 \\
\hline Biperidene & 1 & 1 & 1 & 2 & 1 & 1 & 1 & 1 \\
\hline \multicolumn{9}{|l|}{ COMT inhibitors } \\
\hline Tolcapon & 1 & 1 & 1 & 1 & 1 & 1 & 1 & 1 \\
\hline Entacapone & 1 & 1 & 1 & 1 & 1 & 1 & 1 & 1 \\
\hline
\end{tabular}

$C O M T$ catechol- $O$-methyl transferase, $M A O-B$ monoamine oxidase $\mathrm{B}, 1$ No interactions, 2 non-significant interactions, 3 significant interactions, 4 very significant interactions

parkinsonian agents, individualised hypotensive therapy comprising drugs currently used by the patient should be proposed [43-45].

Because of the lack of interactions, patients in whom preparations of levodopa and benserazide were implemented owing to co-existing PD and arterial hypertension should be prescribed ACE inhibitors, antagonists of $\mathrm{AT}_{1}$ receptor for angiotensin II or antagonists of $\beta$-adrenoreceptors ( $\beta$-adrenolytics) as the first-line agents of antihypertensive treatment.

Although most patients tolerate the therapy with ACE inhibitors well, in the case of patients with PD, special attention should be paid to the potential occurrence of orthostatic hypotension, a potential adverse event. In such an event, withdrawal of ACE inhibitors and replacement with antagonists of $\mathrm{AT}_{1}$ receptor for angiotensin II or $\beta$ adrenoreceptor antagonists should be considered.

The adverse effects of $\beta$-adrenoreceptor antagonists result from their influence on the central nervous system and include fatigue, headache, sleeping disorders, sleeplessness, "living dreams" and depression (rarer in the case of hydrophilic $\beta$-adrenolytics). Moreover, $\beta$-adrenolytics can cause or enhance impotence or loss of libido in some patients. As this type of adverse events is also characteristic for PD, discontinuation of $\beta$-adrenolytics is recommended if evidence for the enhancement of their severity is present.

However, it should be remembered that sudden withdrawal of $\beta$-adrenolytics after long-term use can be reflected by "withdrawal syndrome", presenting with arrhythmia, arterial hypertension and exacerbation of angina pectoris.

The results of previous clinical trials suggest that antagonists of $\mathrm{AT}_{1}$ receptor for angiotensin II are characterised by a lower incidence of adverse events; additionally, their advantages include long-term hypotensive effect and mild onset of action. Therefore, they seem to be the most beneficial antihypertensive agents for individuals with co-existing PD.

Patients receiving dopamine agonists can be prescribed loop diuretics or potassium-sparing diuretics as antihypertensive therapy because of the lack of interaction between these two groups of drugs. In the case of other antihypertensive agents, one should consider their potential interactions with various dopamine agonists and determine whether the patient is receiving combined anti-parkinsonian therapy, including drugs that could potentially interact with those used to treat arterial hypertension. 
Table 8 The occurrence of the interactions between various groups of anti-parkinsonian agents and antihypertensive drugs

\begin{tabular}{|c|c|c|c|c|c|c|c|}
\hline Grupa leków & $\begin{array}{l}\text { Thiazides and } \\
\text { thiazide-like } \\
\text { agents }\end{array}$ & $\begin{array}{l}\text { Loop } \\
\text { diuretics }\end{array}$ & $\begin{array}{l}\text { Potassium- } \\
\text { sparing } \\
\text { diuretics }\end{array}$ & $\begin{array}{l}\text { Angiotensin- } \\
\text { converting enzyme } \\
\text { inhibitors }\end{array}$ & $\begin{array}{l}\text { Antagonists of } \mathrm{AT}_{1} \\
\text { receptor for } \\
\text { angiotensin II }\end{array}$ & $\begin{array}{l}\text { Calcium } \\
\text { channel } \\
\text { antagonists }\end{array}$ & $\begin{array}{l}\text { Antagonists of } \\
\beta \text {-adrenoreceptors } \\
(\beta \text {-adrenolytics) }\end{array}$ \\
\hline $\begin{array}{l}\text { Levodopa } \\
\text { preparations }\end{array}$ & - & - & $-{ }^{a}$ & + & + & - & + \\
\hline $\begin{array}{l}\text { Dopamine } \\
\text { receptor } \\
\text { agonists }\end{array}$ & - & + & + & - & - & - & - \\
\hline $\begin{array}{l}\text { MAO-B } \\
\text { inhibitors }\end{array}$ & + & + & + & + & $+^{\mathrm{b}}$ & $+^{c}$ & - \\
\hline Amantadine & - & $-{ }^{\mathrm{d}}$ & + & + & + & + & + \\
\hline $\begin{array}{l}\text { Cholinolytic } \\
\text { agents }\end{array}$ & - & + & + & + & + & + & - \\
\hline $\begin{array}{l}\text { COMT } \\
\text { inhibitors }\end{array}$ & + & + & + & + & + & + & + \\
\hline
\end{tabular}

COMT catechol- $O$-methyl transferase, $M A O-B$ monoamine oxidase B

+ No interactions, - interactions

${ }^{\text {a }}$ No information in Lexicomp ${ }^{\circledR}$ and Stockley's ${ }^{\circledR}$ databases

${ }^{\mathrm{b}}$ Lexicomp ${ }^{\circledR}$ and Stockley's ${ }^{\circledR}$ include significant interactions between MAO-B inhibitors and $\mathrm{AT}_{1}$ receptor for AT II

${ }^{\mathrm{c}}$ Lexicomp ${ }^{\circledR}$, Stockley's ${ }^{\circledR}$ Micromedex ${ }^{\circledR}$, Cerner Multum ${ }^{\mathrm{TM}}$ and Wolters Kluwer ${ }^{\mathrm{TM}}$ include significant interactions between MAO-B inhibitors and calcium channel antagonists

${ }^{\mathrm{d}}$ No information in Micromedex ${ }^{\circledR}$, Cerner Multum ${ }^{\mathrm{TM}}$ and Wolters Kluwer ${ }^{\mathrm{TM}}$

Dopamine agonists should not be prescribed to patients with dementia, signs of psychosis or mental confusion. Moreover, existing arrhythmia or its history, peripheral circulatory disorders or orthostatic hypotension constitute indications to use these agents with caution.

The dose of dopamine agonists should be increased gradually and blood pressure should be measured on a regular basis. Other groups of anti-parkinsonian agents should be considered for individuals with co-existing hypertension.

MAO-B inhibitors and catechol- $O$-methyl transferase inhibitors can be safely combined with all antihypertensive agents (the only exceptions include concurrent use of acebutolol, bisoprolol, propranolol, or metoprolol and selegiline).

Cholinolytic agents can be safely used with loop diuretics, potassium-sparing diuretics, ACE inhibitors, antagonists of $\mathrm{AT}_{1}$ receptor for angiotensin II and calcium channel antagonists, as they do not interact with these antihypertensive agents.

The occurrence of the interactions between various groups of anti-parkinsonian agents and antihypertensive drugs is summarised in Table 8.

\section{Conclusion}

At present, we lack detailed guidelines regarding the pharmacotherapy of arterial hypertension and the choice of hypotensive agents for patients with PD. Pharmacotherapy of arterial hypertension in individuals with PD has to be individualised. Achieving the desired effect of hypotensive agents and avoiding adverse effects associated with their interaction with anti-parkinsonian agents constitute prerequisites of efficacious antihypertensive therapy.

The differences between British, Polish, and American databases are very interesting. We believe that this information should be taken into account for the patient's wellbeing.

Clinicians working with patients with PD need to know the significance of these interactions to properly advise patients and prevent therapeutic problems.

Acknowledgements None.

Funding None.

Conflicts of interest None.

Open Access This article is distributed under the terms of the Creative Commons Attribution Noncommercial License which permits any noncommercial use, distribution, and reproduction in any medium, provided the original author(s) and the source are credited.

\section{References}

1. Dauer W, Przedborski S. Parkinson's disease: mechanisms and models. Neuron. 2003;39(6):889-909.

2. Goldstein DS. Dysautonomia in Parkinson's disease: neurocardiological abnormalities. Lancet Neurol. 2003;2(11):669-76. 
3. Goldman JG, Postuma R. Premotor and nonmotor features of Parkinson's disease. Curr Opin Neurol. 2014;27(4):434-41.

4. Oka H, Yoshioka M, Onouchi K, Morita M, Mochio S, Suzuki M, et al. Characteristics of orthostatic hypotension in Parkinson's disease. Brain. 2007;130(9):2425-32.

5. Oh YS, Kim JS, Park IS, Song IU, Son YM, Park JW, Yang DW, Kim HT, Lee KS. Association between nocturnal/supine hypertension and restless legs syndrome in patients with Parkinson's disease. J Neurol Sci. 2014;S0022-510X(14):00426-2.

6. Hechtner MC, Vogt T, Zöllner Y, Schröder S, Sauer JB, Binder H, Singer S, Mikolajczyk R. Quality of life in Parkinson's disease patients with motor fluctuations and dyskinesias in five European countries. Parkinsonism Relat Disord. 2014;S1353-8020(14): 00219-3.

7. Custaud MA, de Souza Neto EP, Abry P, Flandrin P, Millet C, Duvareille $\mathrm{M}$, et al. Orthostatic tolerance and spontaneous baroreflex sensitivity in men versus women after 7 days of headdown bed rest. Auton Neurosci. 2002;100(1-2):66-76.

8. Guyenet PG. The sympathetic control of blood pressure. Nat Rev Neurosci. 2006;7(5):335-46.

9. Berganzo K, Diez-Arrola B, Tijero B, Somme J, Lezcano E, Llorens $\mathrm{V}$, et al. Nocturnal hypertension and dysautonomia in patients with Parkinson's disease: are they related? J Neurol. 2013;260(7):1752-6.

10. Pavy-Le Traon A, Amarenco G, Duerr S, Kaufmann H, Lahrmann H, Shaftman SR, et al. The Movement Disorders Task Force review of dysautonomia rating scales in Parkinson's disease with regard to symptoms of orthostatic hypotension. Mov Disord. 2011;26(11):1985-92.

11. Senard JM, Chamontin B, Rascol A, Montastruc JL. Ambulatory blood pressure in patients with Parkinson's disease without and with orthostatic hypotension. Clin Auton Res. 1992;2(2):99-104.

12. Qiu C, Hu G, Kivipelto M, Laatikainen T, Antikainen R, Fratiglioni $\mathrm{L}$, et al. Association of blood pressure and hypertension with the risk of Parkinson disease: the National FINRISK Study. Hypertension. 2011;57(6):1094-100.

13. Goldstein DS, Pechnik S, Holmes C, Eldadah B, Sharabi Y. Association between supine hypertension and orthostatic hypotension in autonomic failure. Hypertension. 2003;42(2):136-42.

14. Miyake Y, Tanaka K, Fukushima W, Sasaki S, Kiyohara C, Tsuboi Y, et al. Case-control study of risk of Parkinson's disease in relation to hypertension, hypercholesterolemia, and diabetes in Japan. J Neurol Sci. 2010;293(1-2):82-6.

15. Vagaonescu TD, Saadia D, Tuhrim S, Phillips RA, Kaufmann H. Hypertensive cardiovascular damage in patients with primary autonomic failure. Lancet. 2000;355(9205):725-6.

16. Flesch M, Erdmann E. The problem of polypharmacy in heart failure. Curr Cardiol Rep. 2006;8(3):217-25.

17. Krause T, Lovibond K, Caulfield M, McCormack T, Williams B. Guideline Development G: management of hypertension: summary of NICE guidance. BMJ. 2011;343:d4891.

18. NICE. NICE clinical guideline. Parkinson's disease: diagnosis and management in primary and secondary care. http://www.nice. org.uk/nicemedia/live/10984/30088/30088.pdf. Accessed 7 Feb 2011.

19. SIGN. Diagnosis and pharmacological management of Parkinson's disease: a national clinical guideline. Available at: http:// www.sign.ac.uk/pdf/sign113.pdf. Accessed 7 Feb 2011.

20. Wile D. Diuretics: a review. Ann Clin Biochem. 2012;49(5):419-31.

21. Craig Brater D. Diuretic therapy. N Engl J Med. 1998;339:387-95.

22. van Blijderveen JC, Straus SM, Rodenburg EM, Zietse R, Stricker BH, Sturkenboom MC, et al. Risk of hyponatremia with diuretics: chlorthalidone versus hydrochlorothiazide. Am J Med. 2014;127(8):763-71.

23. Sica DA, Carter B, Cushman W, Hamm L. Thiazide and loop diuretics. J Clin Hypertens (Greenwich). 2011;13(9):639-43.
24. Salvetti A, Ghiadoni L. Thiazide diuretics in the treatment of hypertension: an update. J Am Soc Nephrol. 2006;17(4 Suppl 2):S25-9.

25. Wargo KA, Banta WM. A comprehensive review of the loop diuretics: should furosemide be first line? Ann Pharmacother. 2009;43(11):1836-47.

26. Bagshaw SM, Delaney A, Haase M, Ghali WA, Bellomo R. Loop diuretics in the management of acute renal failure: a systematic review and meta-analysis. Crit Care Resusc. 2007;9(1):60-8.

27. Haris A, Radó J. Potassium-sparing diuretics (spironolactone, triamterene, amylorid). Orv Hetil. 1996;137(35):1907-14.

28. Brown NJ, Vaughan DE. Angiotensin-converting enzyme inhibitors. Circulation. 1998;97(14):1411-20.

29. Yusuf S, Sleight P, Pogue J, Bosch J, Davies R, Dagenais G. Effects of an angiotensin-converting-enzyme inhibitor, ramipril, on cardiovascular events in high-risk patients: the Heart Outcomes Prevention Evaluation Study Investigators. N Engl J Med. 2000;342(3): 145-53.

30. Jorde UP, Ennezat PV, Lisker J, Suryadevara V, Infeld J, Cukon $\mathrm{S}$, et al. Maximally recommended doses of angiotensin-converting enzyme (ACE) inhibitors do not completely prevent ACEmediated formation of angiotensin II in chronic heart failure. Circulation. 2000;101(8):844-6.

31. Califf RM, Cohn JN. Cardiac protection: evolving role of angiotensin receptor blockers. Am Heart J. 2000;139(1):S15-22.

32. Pfeffer MA, McMurray JJ, Velazquez EJ, Rouleau JL, Kober L, Maggioni AP, et al. Valsartan, captopril, or both in myocardial infarction complicated by heart failure, left ventricular dysfunction, or both. N Engl J Med. 2003;349(20):1893-906.

33. Bainbridge JL, Ruscin JM. Challenges of treatment adherence in older patients with Parkinson's disease. Drugs Aging. 2009;26(2): 145-55.

34. van Zwieten PA. Angiotensin II receptor antagonists (AT1blockers, ARBs, sartans): similarities and differences. Neth Heart J. 2006;14(11):381-7.

35. Sica DA. Pharmacotherapy review: calcium channel blockers. J Clin Hypertens (Greenwich). 2006;8(1):53-6.

36. Brown MJ, Palmer CR, Castaigne A, de Leeuw PW, Mancia G, Rosenthal T, et al. Morbidity and mortality in patients randomised to double-blind treatment with a long-acting calcium-channel blocker or diuretic in the International Nifedipine GITS study: Intervention as a Goal in Hypertension Treatment (INSIGHT). Lancet. 2000;356(9227):366-72.

37. Chen GJ, Yang MS. The effects of calcium channel blockers in the prevention of stroke in adults with hypertension: a metaanalysis of data from 273,543 participants in 31 randomized controlled trials. PLoS One. 2013;8(3):e57854.

38. Chen N, Zhou M, Yang M, Guo J, Zhu C, Yang J, et al. Calcium channel blockers versus other classes of drugs for hypertension. Cochrane Database Syst Rev. 2010(8):CD003654.

39. Rehsia NS, Dhalla NS. Mechanisms of the beneficial effects of beta-adrenoceptor antagonists in congestive heart failure. Exp Clin Cardiol. 2010;15(4):e86-95.

40. Ellison KE, Gandhi G. Optimising the use of beta-adrenoceptor antagonists in coronary artery disease. Drugs. 2005;65(6): 787-97.

41. Wehland M, Grosse J, Simonsen U, Infanger M, Bauer J, Grimm D. The effects of newer beta-adrenoceptor antagonists on vascular function in cardiovascular disease. Curr Vasc Pharmaco. 2012;10(3):378-90.

42. Coats AJ. Beta-adrenoceptor antagonists in elderly patients with chronic heart failure: therapeutic potential of third-generation agents. Drugs Aging. 2006;23(2):93-9.

43. Psaty BM, Lumley T, Furberg CD, Schellenbaum G, Pahor M, Alderman $\mathrm{MH}$, et al. Health outcomes associated with various 
antihypertensive therapies used as first-line agents: a network meta-analysis. JAMA. 2003;289(19):2534-44.

44. Fargel M, Grobe B, Oesterle E, Hastedt C, Rupp M. Treatment of Parkinson's disease: a survey of patients and neurologists. Clin Drug Investig. 2007;27(3):207-18.

45. Tarrants ML, Denarie MF, Castelli-Haley J, Millard J, Zhang D. Drug therapies for Parkinson's disease: a database analysis of patient compliance and persistence. Am J Geriatr Pharmacother. 2010;8(4):374-83.

46. Whelton PK, Appel LJ, Espeland MA, Applegate WB, Ettinger $\mathrm{WH}, \mathrm{Jr}$, Kostis JB, et al. Sodium reduction and weight loss in the treatment of hypertension in older persons: a randomized controlled trial of nonpharmacologic interventions in the elderly (TONE): TONE collaborative research group. JAMA. 1998;279: 839-46.

47. National Institute of Clinical Excellence. Hypertension: management of hypertension in adults in primary care. http://www. nice.org.uk/CG034. Accessed on 10 Dec 2010.

48. Moser M, Pickering T, Sowers JR. Combination drug therapy in the management of hypertension: when, with what, and how? J Clin Hypertens. 2000;2:94-8. 